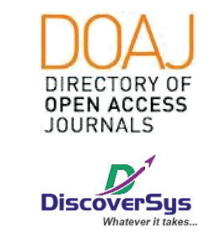

Published by DiscoverSys

\section{Characteristic overview of aplastic anemia at Sanglah Hospital, Bali-Indonesia in 2017-2018}

\author{
Komang Agus Widhy Utama Putra, ${ }^{1 *}$ A.A Ngurah Subawa, ${ }^{2}$ A.A Wiradewi Lestari ${ }^{2}$
}

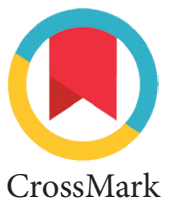

CrossMark

\title{
ABSTRACT
}

Background: Aplastic anemia is a rare disease of anemia which characterized by pancytopenia due to spinal cord hypoplasia. This can occur in people of any age, race, and gender with different degree of severity, with incidence rate is two until three times higher in Asia than the West. This study aims to determine the characteristic of aplastic anemia based on age, gender, laboratory examination, and severity in Sanglah Hospital.

Methods: This research is a cross sectional descriptive study with sources of data were medical records of aplastic anemia patients at Sanglah Hospital in the last 2 years, 2017-2018. Distribution of research variables is gender, age, laboratory examination, and severity. Results:The result showed that 11 data were $6(55 \%)$ male and 5 female $(45 \%)$, with the mean age was $48 \pm 14$ years. The highest incidence occurred in the age range of $26-60$ years old with 7 patients $(64 \%)$. In this study the average hemoglobin level obtained was $9.94 \pm 1.46 \mathrm{~g} / \mathrm{dL}$ with range between 6.65 to $12.49 \mathrm{~g} / \mathrm{dL}$. The average number of leukocytes was $11.91 \pm 24.52 \times 10^{9} \mathrm{~L}$ with range of leukocytes is $1.99-84.58 \times 10^{9} / \mathrm{L}$. The average number of absolute Neutrophils and percent was $1.53 \pm$ $1.52 \times 10^{9} / \mathrm{L}$ and $25.99 \pm 25.79 \%$ with range between $0.06-4.53 \times 10^{\circ} / \mathrm{L}$ and $2.3-70.83 \%$. The average platelet count was $24.77 \pm 11.35 \times 10^{9} / \mathrm{L}$ with range between $4.25-42.58 \times 10^{9} / \mathrm{L}$. The highest cases were nonsevere aplastic anemia (NSAA) with 7 people (64\%).

Conclusion: The value of laboratory parameters for complete blood examination (leukocytes, platelets, hemoglobin, and neutrophils) in patients with aplastic anemia at Sanglah General Hospital is still very low, so it is a challenge for clinicians to carry out treatment of aplastic anemia and management related complications.
${ }^{1}$ Faculty of Medicine, Udayana University, Bali-Indonesia ${ }^{2}$ Clinical Pathology Department, Faculty of Medicine-Sanglah General Hospital, Bali-Indonesia

\section{*Correspondence to:}

Komang Agus Widhy Utama

Putra,Faculty of Medicine, Udayana University, Bali-Indonesia 9eagus01@gmail.com
Received: 2019-03-06 Accepted: 2019-04-11 Published: 2019-08-01

Keywords: Aplastic anemia, characteristic, gender, age, laboratory examination, severity.

Cite This Article: Putra, K.A.W.U., Subawa, A.A.N., Lestari, A.A.W. 2019. Characteristic overview of aplastic anemia at Sanglah Hospital, BaliIndonesia in 2017-2018. Intisari Sains Medis 10(3): 497-500. D0I: 10.15562/ism.v10i3.429

\section{INTRODUCTION}

Aplastic anemia is the archetype of the human bone marrow failure. ${ }^{1}$ It was first described by Paul Ehrlich in 1888 which was found in pregnant woman. Generally, it is an anemia characterized by pancytopenia or bicytopenia peripheral blood due to abnormalities of the spinal cord in the form of hypoplasia without infiltration, suppression, and displacement of bone marrow itself. ${ }^{2}$ On the easier way it is described as the syndrome when the bone marrow produces too few numbers of all types of blood cells. This problem can cause the drop of hemoglobin level because of low number of erythrocytes, be susceptible to infection because of low number of leukocytes, and cause clotting of blood problem because of platelet deficiency.

This can occur in people of any age, race, and gender. But it is more common among children, teenagers, and young adults. It belongs to a rare disorder with incidence ranges from 2 to 6 cases per 1 million inhabitants per year. It is more likely happen in Asia for 2-3 times than in West with range of age is between 15-25 years old but a small number shows after 60 years old. In Indonesia, the number cases of Aplastic Anemia per year is still unclear, and by the data of 2002, the incidence of Aplastic Anemia among others hematological disease in children such as thalassemia and hemolytic, the percentage was $10 \%{ }^{3}$
A few decades ago, Aplastic Anemia was globally included in fatal disease. But nowadays it can be cured or ameliorated by stem-cell transplantation or immunosuppressive drug therapy. Most cases are immune-mediated with activated type 1 cytotoxic $\mathrm{T}$ cells implicated. Although remains problematic, clonal hematologic's relapse because of immunosuppression with anti-thymocyte globulins and cyclosporine is still effective at restoring blood-cell production in the majority of patients. Curatively, allogeneic stem-cell transplant from sibling histocompatible donors is in the popular way of young patients with aplastic anemia, with challenges from how to extend the benefits of the transplantation to older patient or has not family donors. ${ }^{4}$

Although aplastic anemia is one of the rarest types of anemia, it is still can be considered as a problem nowadays, and the prevalence of this disease is still unclear especially in Indonesia due to lack of case study, but as said above that aplastic anemia is more likely to happen in South East Asia countries 2-3 times higher than Europe or America, so author thought that the case study to do research of aplastic anemia in Indonesia, especially in Bali for at least 2-3 years back is important to know the progress and characteristics of this disease based 
on age, gender, and also severity of aplastic anemia, which will be done at Sanglah Hospital.

\section{METHOD}

This study is a descriptive prospective study to determine the characteristic overview of aplastic anemia based on age, gender, hemoglobin level, leukocyte count, absolute neutrophil count, neutrophil percentage, platelet count, and its severity at Sanglah Hospital in 2017-2018. Inclusion criteria are Aplastic anemia patients who are registered in medical records at Sanglah General Hospital in January 2017 - August 2018. The medical records consist of age, gender, and classification of aplastic anemia. Data analysis in this study is using descriptive analysis which is by describing numerically and graphically (in the form of table or graph) the number of cases and characteristic overview of aplastic anemia.

\section{RESULT}

Based on the results of the study there were 11 medical records data of patients with a diagnosis of aplastic anemia treated from January 2017 until August 2018 at Sanglah Hospital (Table 1). There were 6 people with

Table 1 Baseline Characteristics

\begin{tabular}{|c|c|}
\hline Variable & Case $n=11$ \\
\hline \multicolumn{2}{|l|}{ Gender } \\
\hline Male & $6(55 \%)$ \\
\hline Female & $5(45 \%)$ \\
\hline Age (Year) mean \pm SD & $48 \pm 14$ \\
\hline $19-25$ & $1(9 \%)$ \\
\hline $26-60$ & $7(64 \%)$ \\
\hline$>60$ & $3(27 \%)$ \\
\hline $\begin{array}{l}\text { Average Hemoglobin Level }(\mathrm{Hb})(\mathrm{g} / \mathrm{dL}) \\
(\text { mean } \pm \mathrm{SD})\end{array}$ & $9.94 \pm 1.46$ \\
\hline Average Leukocyte Count $\left(\mathrm{x} 10^{9} / \mathrm{L}\right)($ mean \pm SD $)$ & $11.91 \pm 24.52$ \\
\hline 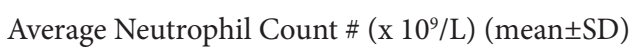 & $1.53 \pm 1.52$ \\
\hline Average Neutrophil Count (\%) $($ mean \pm SD) & $25.99 \pm 25.79$ \\
\hline Average Platelet Count $(\mathrm{x} \mathrm{10} / \mathrm{L})($ mean \pm SD) & $24.77 \pm 11.35$ \\
\hline Range of Hemoglobin Level (g/dL) & $6.65-12.49$ \\
\hline Range of Leukocyte Count (x 109/L) & $1.99-84.58$ \\
\hline Range of Neutrophil Count \# (x 109/L) & $0.06-4.53$ \\
\hline Range of Neutrophil Count (\%) & $2.3-70.83$ \\
\hline Range of Platelet Count (x 109/L) & $4.25-42.58$ \\
\hline \multicolumn{2}{|l|}{$\begin{array}{l}\text { Aplastic Anemia Classification Based on Absolute } \\
\text { Neutrophil Count (\#) }\end{array}$} \\
\hline Non Severe Aplastic Anemia (NSAA) & $7(64 \%)$ \\
\hline Severe Aplastic Anemia (SAA) & $3(27 \%)$ \\
\hline Very Severe Aplastic Anemia (VSAA) & $(9 \%)$ \\
\hline
\end{tabular}

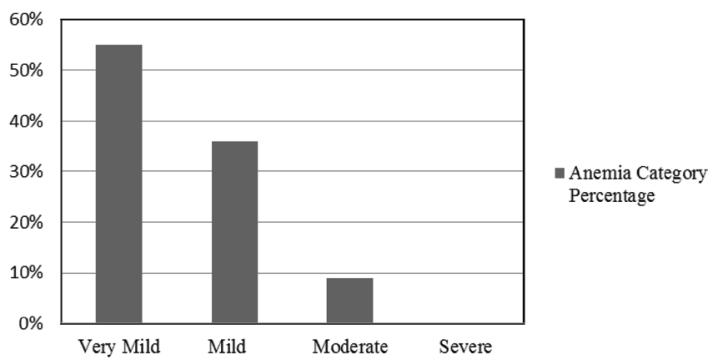

Figure 1 Distribution of Aplastic Anemia Patients by Anemia Category

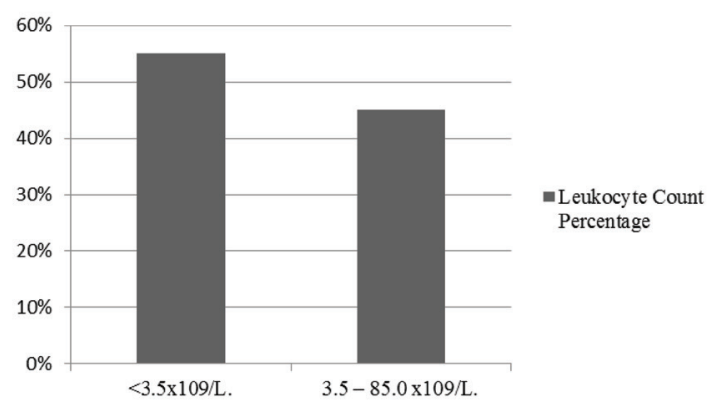

Figure 2 Distribution of Aplastic Anemia Patients by Leukocyte Count

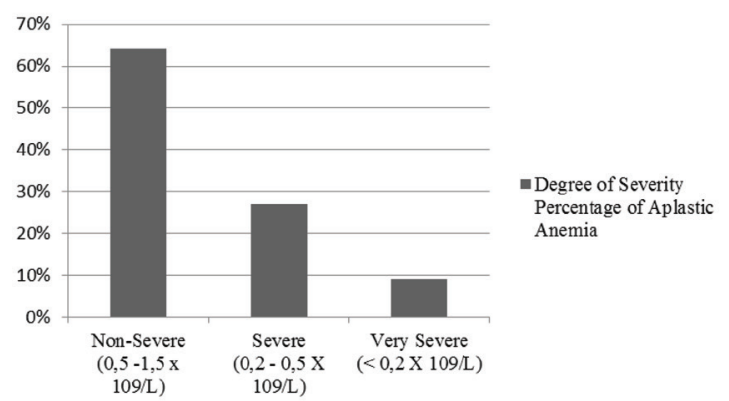

Figure 3 Distribution Of Aplastic Anemia Patients With Neutrophil Count By Its Severity

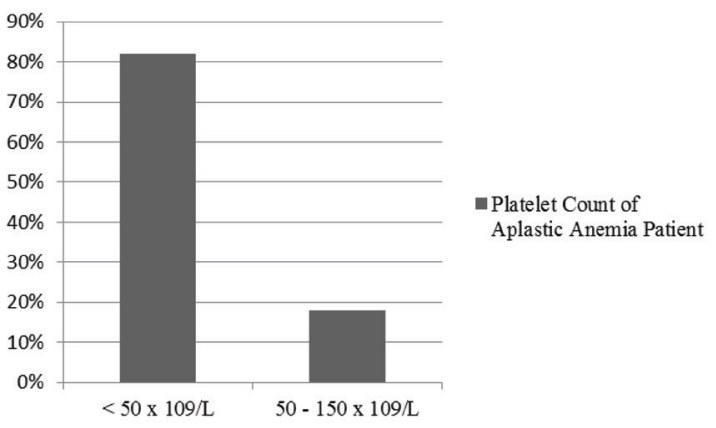

Figure 4 Distribution of Aplastic Anemia Patients by Platelet Count

very mild anemia (55\%), 4 people with mild anemia (36\%), 1 person with moderate anemia (9\%) and no patient suffered severe anemia (Figure 1). The number of leukocytes in this study was divided into two categories namely less than $3.5 \times 10^{9} / \mathrm{L}$ and the number of leukocytes between $3.5 \times 10^{9} / \mathrm{L}-85.0 \times 10^{9} / \mathrm{L}$ so 
that of the 11 data aplastic anemia patients obtained as many as 6 people (55\%) the number of leukocytes is less than $3.5 \times 10^{9} / \mathrm{L}$ and as many as 5 people $(45 \%)$ the number of leukocytes is in the range of $3.5 \times$ $10^{9} / \mathrm{L}-85.0 \times 10^{9} / \mathrm{L}$ (Figure 2). The degree of severity of aplastic anemia in this study is divided into 3 categories, which are very severe aplastic anemia with absolute neutrophil range less than $0.2 \times 10^{9} / \mathrm{L}$, severe aplastic anemia with the range of neutrophils absolute $0.2-0.5 \times 10^{9} \mathrm{~L}$ and non severe aplastic anemia with the range of neutrophils between $0.5-1.5 \times 10^{9} / \mathrm{L}$. In this study, 11 data from aplastic anemia patients found that aplastic anemia patients with non-severe category were 7 people (64\%), severe aplastic anemia were 3 people $(27 \%)$ and very severe category was 1 person (9\%) (Figure 3).

Platelet counts of aplastic anemia patients were divided into 2 categories: platelet counts less than $50 \times 10^{9} / \mathrm{L}$ and platelet counts between $50-150 \times$ $10^{9} / \mathrm{L}$, which resulted in 9 people $(82 \%)$ platelets less than $50 \times 10^{9} / \mathrm{L}$ and 2 other people $(18 \%)$ had platelet counts in the range of $50-150 \times 10^{9} / \mathrm{L}$ (Figure 4).

\section{DISCUSSION}

Based on age categories, in this study were categorized into 3 age groups where the most common cases were in the 26-60 years old group, with 7 patients $(64 \%)$ followed by at the age of $>60$ years old with 3 patients (27\%), and lastly obtained is between the ages of 19 to 25 years old with only 1 person.

When compared with research by Vaht et al. ${ }^{5}$ conducted at the National Patient Registry, in Sweden showed the number of aplastic anemia patients peaked in patients aged 15-20 years with an incidence of 2.87 cases per million population per year and one patient over the age of 60 years 4.36 cases per million population per year. On the other hand, in addition to the study by Montane et al. ${ }^{6}$ showed the highest proportion of patients at the age of 45 to 64 years (59.3\%) and ages 2 to 14 years $(48.3 \%)$.

In the research conducted by Wang et al. ${ }^{7}$ the proportion of aplastic anemia patients often occurred at the age of 18 to 82 years, with a median of 35 years, in which patients aged less than 40 years old counted to 80 people (56.3\%) and 23 patients $(16.2 \%)$ at the age of $\geq 60$ year.

The number of cases of aplastic anemia based on age in this study is not much different from other studies, in this study the highest number of cases was seen in the age range between 26 to 60 years old, which can occur because age is one of the risk factors for aplastic anemia.

Based on gender category in this study anemia aplastic are more common in men compared to women. Another study by Montane et al. ${ }^{6}$ which is more dominant is male patients (123 person, $52.3 \%$ ) whereas in the study by Vaht et al. ${ }^{5}$ shows a different finding, which shows that the cases of aplastic anemia obtained are female compared to male (133 people, $52 \%$ ), which can occur because of the many influences of genetics, different tribes, different lifestyles and environmental factors whose influence is different to each other.

Based on the results of the study showed aplastic anemia patients had the most very mild anemia with 6 patients (55\%), whose $\mathrm{Hb} 10 \mathrm{~g} / \mathrm{dl}$ or higher, followed by mild anemia category with 4 patients (36\%).

In a study by Ashwini et al. ${ }^{8}$ in the Department of Pathology at Bangalore medical college and research institute, India showed that of 15 cases of Aplastic Anemia there were 6 cases with $\mathrm{Hb}$ less than $5 \mathrm{~g} / \mathrm{dL}$ and 9 other cases had hemoglobin levels between 5 $\mathrm{g} / \mathrm{dL}-10 \mathrm{~g} / \mathrm{dL}$.

Based on the diagnosis criteria for Aplastic Anemia from the International Agranulocytosis and Applied Anemia Study Group (IAASG), it is stated that for the diagnosis of Aplastic Anemia Leukocyte levels are less than $3.5 \times 10^{9} / \mathrm{L} .{ }^{9}$ Meanwhile the total normal leukocyte range for adults is 4.00 $11.00 \times 10^{9} / \mathrm{L}$. Based on this, the cut-off point used to describe leukopenia is less than $3.5 \times 10^{9} / \mathrm{L}$. So we got 2 categories for the number of leukocytes, namely the number of leukocytes less than $3.5 \times$ $10^{9} / \mathrm{L}$ as many as 6 people (55\%) and as many as 5 other people $(45 \%)$ of the number of leukocytes in the range of $3.5 \times 10^{9} / \mathrm{L}-85.0 \times 10^{9} / \mathrm{L}$.

Normal platelets count have a range between $150 \times 10^{9} / \mathrm{L}-400 \times 10^{9} / \mathrm{L}$, meanwhile the diagnosis of Aplastic Anemia is based on the International Agranulocytosis and Aplastic Anemia Study Group criteria (IAASG) which states that the diagnosis of aplastic anemia must be meet one of the three existing criteria, one of which is a platelet count of less than $50 \times 10^{9} / \mathrm{L}^{.911}$

When compared with research by Ashwini et al. ${ }^{8}$ which showed the number of patients with platelets less than $50 \times 10^{9} / \mathrm{L}$ (13 person, $86.7 \%$ ) more than in patients with platelet counts between $50-150 \times$ $10^{9} / \mathrm{L}$ ( 2 person, $13.3 \%$ ). In addition, the results of this study are in accordance with the criteria based on IAASG which shows the diagnosis of aplastic anemia must meet one of the 3 categories of IAASG, one of which is platelets less than $50 \times$ $10^{9} / \mathrm{L}$, platelets in the range of $50-150 \times 10^{9} / \mathrm{L}$ even though more than $50 \times 10^{9} / \mathrm{L}$, this range is still a category of thrombocytopenia.

The normal criteria for absolute Neutrophils are $2.5-7.5 \times 10^{9} / \mathrm{L}$. Meanwhile, the classification of aplastic anemia is divided into 3 categories, namely non-severe, severe and very severe. This category 
is adjusted to the study by Guinan in 2011 which states that for the severe category must meet the following criteria, which neutrophil count $<0.5 \times$ $10^{9} / \mathrm{L}$ and platelet count $<20 \times 10^{9} / \mathrm{L}$. Meanwhile for very severe it meets the same criteria as before but the number of neutrophils must be $<0.2 \times 10^{9} / \mathrm{L}^{10}$

When compared with other studies such as in the study of Wang et al. ${ }^{7}$ found absolute neutrophil mean at SAA was $0.37 \pm 0.40 \times 10^{9} / \mathrm{L}$ and at NSAA was $0.89 \pm 0.52 \times 10^{9} / \mathrm{L}$. The mean hemoglobin at SAA was $71.9 \pm 21.4 \times 10^{9} / \mathrm{L}$ at NSAA was $76.2 \pm$ $24.8 \times 10^{9} / \mathrm{L}$ while for platelets it was obtained on average at SAA $19.9 \pm 18.1 \times 10^{9} / \mathrm{L}$ and at NSAA are $31.4 \pm 19.0 \times 10^{9} / \mathrm{L}$

Limitation of study is a retrospective descriptive cross sectional study. the data obtained is data derived from sanglah hospital medical records, but of the 28 data only 11 data can be examined so that it will affect the accuracy and credibility of the results of the study besides medical record data is secondary data that can cause bias in research.

\section{CONCLUSION}

Based on sociodemography, the average age of aplastic anemia patients was 48 years man are more common than female. In this study the average hemoglobin level obtained was $9.94 \pm 1.46 \mathrm{~g} / \mathrm{dl}$ with a range of $6.65-12.49 \mathrm{~g} / \mathrm{dl}$. The mean number of leukocytes is $11.91 \pm 24.52 \times 10^{9} / \mathrm{L}$ with a range of $1.99-84.58 \times 10^{9} / \mathrm{L}$. The average number of absolute and percent neutrophils is $1.53 \pm 1.52 \times$ $10^{9} / \mathrm{L}$ and $25.99 \pm 25.79 \%$ with a range between $0.06-4.53 \times 10^{9} / \mathrm{L}$ and $2.3-70.83 \%$. The mean number of platelets is $24.77 \pm 11.35 \times 10^{9} / \mathrm{L}$ with a range between $4.25-52.58 \times 10^{9} / \mathrm{L}$. The classification of aplastic anemia based on its severity is divided into 3 groups that are non-severe, severe, and very severe. In the nSAA, there were 7 patients $(64 \%)$, SAA category 3 patients $(27 \%)$ and vSAA category 1 patient $(9 \%)$.

\section{CONFLICT OF INTEREST}

The author declares there is no conflict of interest regarding the publication of the article.

\section{FUNDING}

Current study doesn't receive any specific grant from government or any private sectors.

\section{ETHICAL ASPECT}

This study has been approved by Ethics Committee Faculty of Medicine Udayana University/Sanglah General Hospital with references number LB.02.01/ XIV.2.2.1/11534/2018.

\section{REFERENCES}

1. Young NS, Scheinberg P, Calado RT. Aplastic anemia. Curr Opin Hematol. 2008;15(3):162-168.

2. Niemeyer CM, Baumann I. Classification of childhood aplastic anemia and myelodysplastic syndrome. Hematology. 2011;1:84-89.

3. Moore CA, Krishnan K. Aplastic anemia. NCBL Book Shelf [Internet]. Diakses 6 Juli 2017. Tersedia di: https:// www.ncbi.nlm.nih.gov/books/NBK534212/.

4. Scheinberg P, Wu CO, Nunez O, Scheinberg P, Carol B, Sloand EM, et al. Treatment of severe anemia with a combination of horse antithymocyte globulin cyclosporine, with or without sirolimus: a prospective randomized study. Haematologica. 2009;94(3):348-354.

5. Vaht K, Goransson M, Carlos K, Isaksson C, Lenhoff S, Sandstedt A, et al. Incidence and outcome of acquired anemia: real-world data from patients diagnosed in Sweden from 2000-2011. Haematologica. 2017;102(10):1683-1690.

6. Montane E, Ibanez L, Vidal X, Ballarin E, Puig R, Garcia N, et al. Epidemiology of aplastic anemia: a prospective multicenter study. Haematologia. 2008;93(4):518-523.

7. Wang CL, Shao Z. Aplastic anemia in China. J Transl Int Med. 2018;6(3):134-137.

8. Ashwini BR, Siddiq MA. Aplastic Anemia in a developing country: the present and the need. National Journal of Laboratory Medicine. 2016;5(3):PO08-PO10.

9. Bakta IM, Gematologi klinik ringkas. Jakarta: Penerbit Buku Kedokteran EGC; 2006. h. 98-110.

10. Guinan EC. Diagnosis and management of aplastic anemia. Hematology Am Soc Hematol Educ Program. 2011;2011:76-81.

11. Singh $\mathrm{P}$, Khan S, Mittal R. Anemia during pregnancy in the women of western Nepal. Bali Medical Journal. 2013;2(1):14-16.

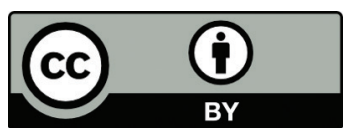

This work is licensed under a Creative Commons Attribution 